led to confrontations but the matter has not been resolved and is obviously detrimental to patient care. An element of 'democracy' has been introduced in the overall medical care of patients and the doctor has found himself in the minority with his views ignored and often overruled. Although the Responsible Medical Officer, he has been placed in a dilemma by not being able to give the patient the best possible medical treatment. The DHSS has never clarified this matter. This erosion of clinical autonomy is making a mockery of patient care as it gives the doctor responsibility but not authority in the treatment programme.

In the 'long-stay hospital' the situation has become acute, especially in view of the closure programme. No longer are the RMO's views on patients' suitability for transfer or discharge sought. Deficiencies in paramedical services for hospital patients remain unremedied and the doctor's dream of upgrading medical care and treatment remains unfulfilled. Such despair cannot be a good thing for the National Health Service as a whole or the country at large.

Brockhall Hospital

U. J. DEY

Old Langho

Nr Blackburn, Lancs.

\section{Current norm for consultant psychiatrists in mental handicap}

DeAR Sirs

I am writing to express concern regarding the current norm for consultant psychiatrists in mental handicap (Bulletin, April 1988, 12, 155) and the College's role to influence at Regional level some of the "overloaded' jobs. The current norm of 1 to 200,000 is at least over a decade old and it was expected that the College would have recommended an improved figure of at least 1 to 100,000 if not better, parallel to other subspecialties of psychiatry. At present in East Dorset (Bournemouth) there are 11 general psychiatrists, two psychogeriatricians and three child psychiatrists against one consultant psychiatrist in mental handicap for a population of 430,000 .

I would like to generate a constructive argument about some of the posts having catchment areas of over 650,000 . How can one do justice to the services with this sort of catchment area? I am sure that the job descriptions of this kind of post must have gone through for an approval to the Regional Adviser in Psychiatry or the local professor's department. They should either force the Region to improve on the job or refuse to give College support and approval for the job description. In certain districts the job description is changed after approval of the job for advertisement, which I feel should be considered seriously, and the Regions should be advised not to do that and instead re-submit the job description for approval. The College's representative on the Appointment Committees should also look into these factors as the candidates cannot always grasp all information on a preliminary visit and may not be aware of 'grey' areas of the job.

I would suggest the following:

1. change the norm to I WTE to 100,000

2. strict screening of job description before approval and advertisement

3. frequent review of the situation

4. if possible to 'blacklist' the Region or District which does not improve the job descriptions or comply with the College guidelines.

G. S. SARNA

\section{East Dorset Mental Handicap Services}

Bournemouth

\section{Appropriate use of Sections 2 and 3 of the Mental Health Act 1983}

\section{DEAR SirS}

In my letter (Bulletin, November 1987) I said that I would welcome a statement from the Commissioners on the controversial matter of the appropriate use of Sections 2 and 3 of the Mental Health Act 1983, and that I hoped that their recommendations would be on the lines set out by Dr Aaronricks (Bulletin, June 1987). I would therefore like to welcome the letter from the Chairman of the Mental Health Review Tribunals (Bulletin, May 1988). As may be surmised from my correspondence, I am totally in agreement with the distinctions made by the Chairman between the appropriate use of Section 2 and Section 3 and if I may be so bold as to speak for Dr Aaronricks, I believe that these were the distinctions that he was also emphasising in his correspondence.

Hinchingbrooke Hospital, Huntingdon

DONALD BERmingham and Fulbourn Hospital, Cambridge

\section{Wider use of benzodiazepines}

DEAR Sirs

The statement on benzodiazepines which you published in the Bulletin, (May 1988, 12, 205) is quite misleading. It reads as if benzodiazepines are only used as anxiolytics and hypnotics, and ignores the wide potential for the use of benzodiazepines in other areas of medicine. Benzodiazepines are widely used in neurological practice, in particular for their muscle relaxant and also anticonvulsant properties. A number of benzodiazepines are now used routinely in the management of epilepsy, including clonazepam and more recently clobazam. The latter drug, a 1,5 